\title{
Interpretation of Gravity Data using 3D Euler Deconvolution, Tilt Angle, Horizontal Tilt Angle and Source Edge Approximation of the North-West Himalaya
}

\author{
Gopal K. GHOSH \\ Oil India Limited, Duliajan, Assam, India \\ e-mail:gk_ghosh@yahoo.com
}

\begin{abstract}
The collision of the Indian plate and the Eurasian plate created shortening and imbrications with thrusting and faulting which influences northward tectonic movement. This plate movement has divided the Himalaya into four parts, viz. Outer Himalaya, Lesser Himalaya, Greater Himalaya, and Tethys Himalaya. The crystalline basement rock plays an imperative role for structural and tectonic association. The study has been carried out near Rishikesh-Badrinath neighborhood in the northwestern part of the Himalayan girdle with multifarious tectonic set up with thrusted and faulted geological setting. In this study area, 3D Euler deconvolution, horizontal gradient analysis, tilt angle (TILT) and horizontal tilt angle (TDX) analysis have been carried out using gravity data to delineate the subsurface geology and heterogeneity in the northwestern part of Himalaya. The Euler depth solutions suggest the source depth of about $12 \mathrm{~km}$ and various derivative analyses suggest the trend of the delineation thrust-fault boundaries along with the dip and strike direction in the study area.
\end{abstract}

Key words: Euler deconvolution, tilt angle (TILT), horizontal tilt angle (TDX), gradient derivative, Indian Plate.

Ownership: Institute of Geophysics, Polish Academy of Sciences;

(C) 2016 Ghosh. This is an open access article distributed under the Creative Commons Attribution-NonCommercial-NoDerivs license,

http://creativecommons.org/licenses/by-nc-nd/3.0/. 


\section{INTRODUCTION}

The area of study, situated in the Rishikesh-Badrinath, extends from $30^{\circ} \mathrm{N}$ to $31.2^{\circ} \mathrm{N}$ and $78^{\circ} \mathrm{E}$ to $80^{\circ} \mathrm{E}$ (Fig. 1). The tectonic movements of the Indian plate and the Eurasian plate caused overlapping, shortening, stratigraphic changes, and tectonic setting in the north-western part of Himalayan belt (Leech et al. 2005). The Himalaya can be divided into four parts: Outer Himalaya, Lesser Himalaya, Greater or Higher Himalaya, and Tethys Himalaya (Gansser 1964). The Main Frontal Thrust (MFT) to the south and the Main Boundary Thrust (MBT) to the north are referred to as Outer Himalaya and have molassic Siwalik super-groups of Miocene and Pliocene ages. The Lesser Himalaya is also subdivided by the MBT to the south and the Main Central Thrust (MCT) to the north and a thick pile of highly folded Proterozoic sedimentary strata with older crystalline rocks (Gansser 1964). The Greater or Higher Himalaya is demarcated by the MCT to its south and the Dar-Martoli Fault or Tethys Fault or the South Tibetan Detachment (STD) to the north. The Tethys Himalaya includes thick pile of sedimentary rocks of Cambrian to lower Eocene ages. The structural and petrological aspects have been studied by Le Fort (1975). Structural and tectonic interpretations of parts of Himalaya have been carried out by Molnar et al. (1977) using some geophysical observations. The MCT and its quartz-rich tectonites in Central

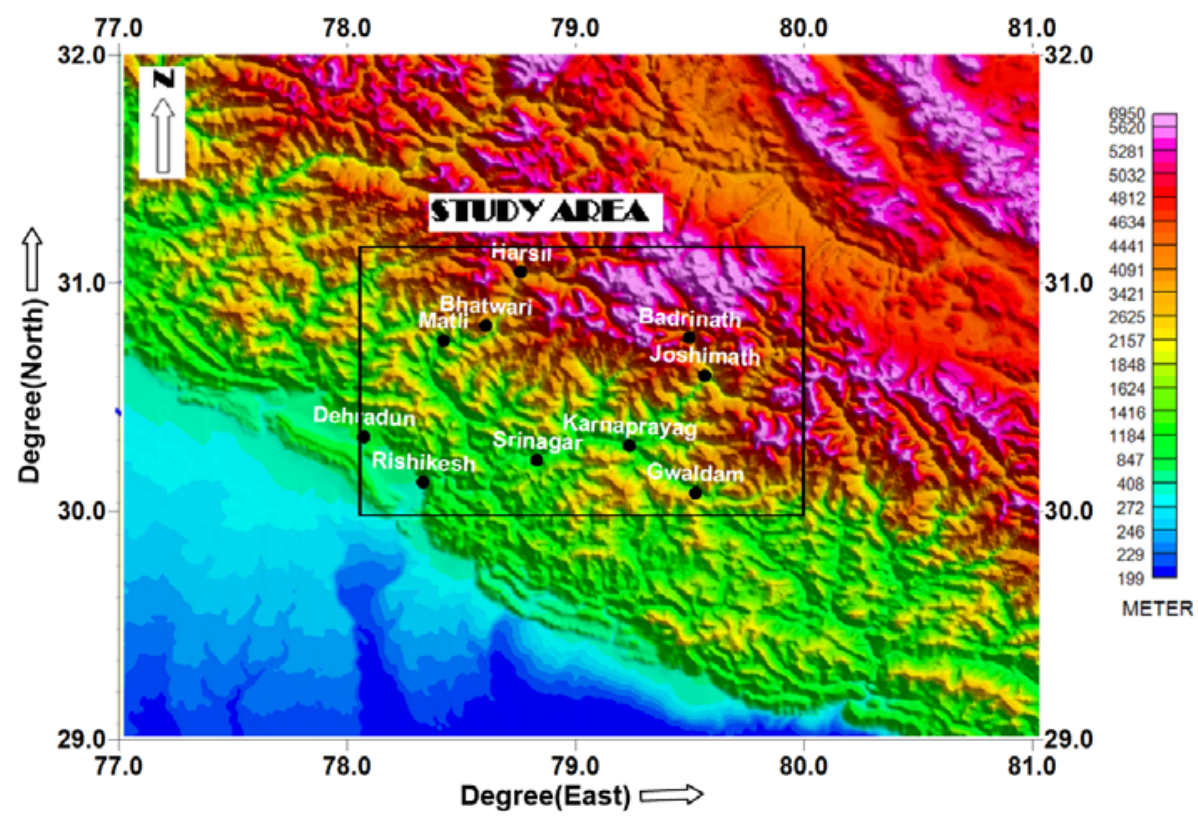

Fig. 1. Computer generated map showing the topography of the study area and its surroundings. 
Nepal have been studied by Bouchez and Pecher (1981). The deformation pattern of leucogranites of the Crystalline MCT (CMCT) sheet in southern Tibet was studied by Burg et al. (1984). Grasemann et al. (1999) represented kinematic flow of decelerating strain path analysis and extrusion of orogenic wedges from the MCT of north-west Himalaya. Beaumont et al. (2001) considered the extrusion of low-viscosity crustal channel in the Himalayan tectonics as coupled to focus surface denudation. Vannay and Grasemann (2001) made it clear that the Himalayan inverted metamorphism and syncconvergence extension are a consequence of a general shear extrusion. Bhattacharya and Weber (2004) elucidated the shear deformation in the MCT zone of north-western Himalaya region.

The crystalline basement rock plays a vital role for structural and tectonic involvement which is unperturbed with tectonic movement and deformation. In this text we have dealt with "basement rocks" or "crystalline basement rocks" which are basically of metamorphic or igneous origin and are termed "granitic basement", generally covered by sedimentary rocks or sedimentary basin. Generally, $S$-wave velocity starts around $3500 \mathrm{~m} / \mathrm{s}$ and $P$ wave velocity starts around $6000 \mathrm{~m} / \mathrm{s}$ in this layer. This is the high velocity layer. It is generally described as the Indian Shield situated below the sedimentary layers and named the Indian Crystalline Basement.

The study area is located near Rishikesh-Badrinath neighborhood in the north-western part of the Himalayan girdle with multifarious tectonic set up with thrusted and faulted geology. The estimation of crystalline basement depth in folded and thrusted areas of such kind is very difficult. Different authors (Khattri et al. 1989, Reddy and Arora 1993, Bhattacharya and Weber 2004, Arora et al. 2007) worked for the estimation of basement depth, but the results are not very specific and clear.

Ghosh and Singh (2014) studied the Indian crystalline basement depth in the Dehradun-Badrinath area using spectral analysis and 2D Euler deconvolution technique of gravity data along the few selected profiles. The results are obtained using 2D approach and some geological models have been proposed for shallow crustal configuration based on the gravity data (Ghosh and Singh 2014). The average basement depth estimated was $11.27 \mathrm{~km}$ using 2D spectral analysis of gravity data. The 2D Euler de-convolution suggests basement depth varying from 10 to $15 \mathrm{~km}$ across the profile from SW to NE in the study area along the three selected profiles. The study suggests that most of the cluster points were located within 10 to $15 \mathrm{~km}$ depth range. However, the results provided do not meet in terms of holistic vision to get details in 3D interpretation.

In continuation, to study the area in terms of 3D depth investigation, we have used the published gravity data (Qureshy et al. 1974). The old gravity data have been digitized and re-interpreted in terms of geophysical conse- 


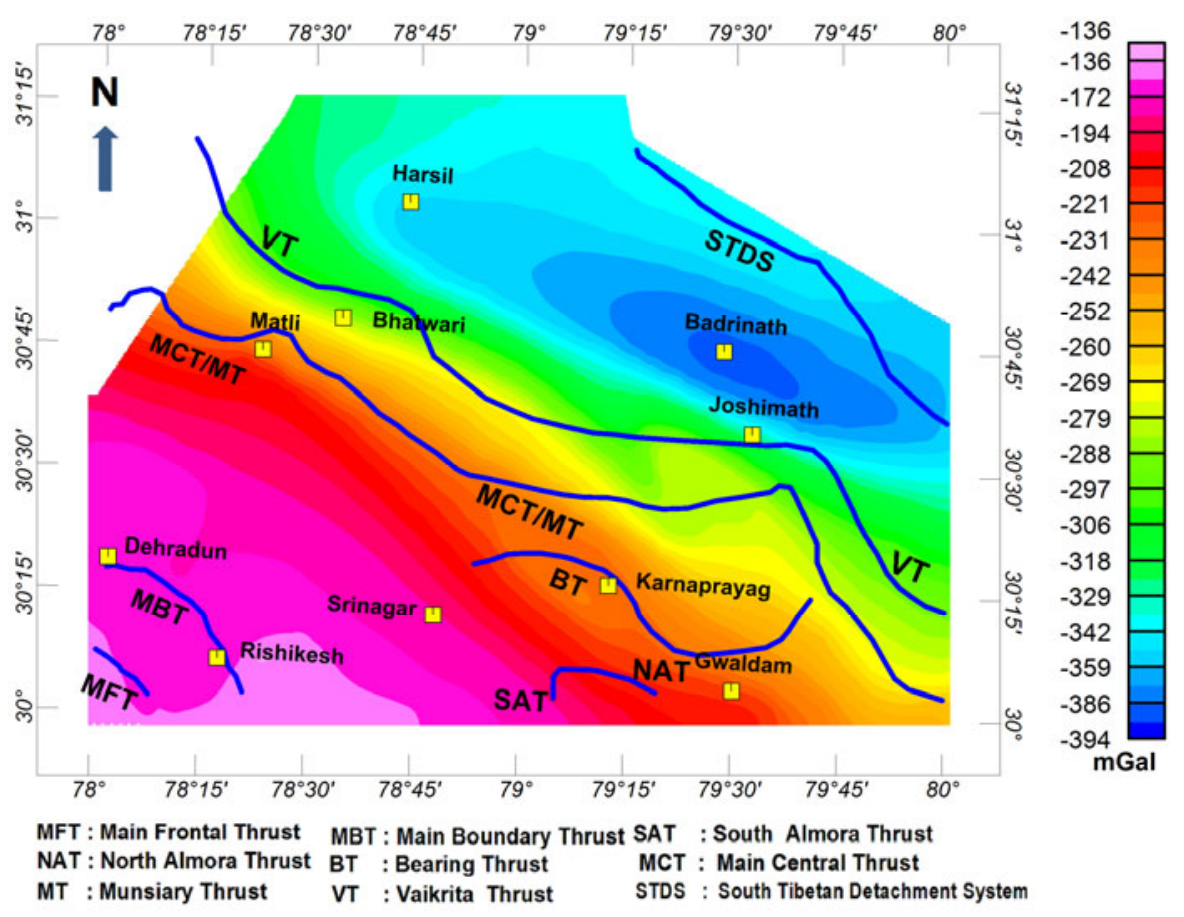

Fig. 2. Bouguer gravity anomaly map (after Qureshy et al. 1974) digitized and replotted (Ghosh and Singh 2014). The colour bar denotes the Bouguer gravity anomaly values. Higher gravity value observed at Rishikesh, Srinagar, and Dehradun areas. Lower gravity values are observed at Badrinath, Harsil, and Joshimath areas. Moderate gravity value observed at Gwaldam in the central part orienting NW-SE trends.

quences. The contour maps have been generated using minimum curvature gridding with a grid spacing of $1000 \mathrm{~m}$. The data has been further applied to $3 \times 3$ convolution matrix for better imaging. The different thrust locations (Ghosh and Singh 2014) are superimposed on the digitized gravity anomaly map (Fig. 2).

In the present study, various gravity gradients are interpreted and results are correlated. The horizontal gradient, tilt angle derivative (TILT), horizontal tilt angle derivative (TDX), and Euler deconvolution (ED) of gravity data have been used to delineate the subsurface geology, identifying the subsurface heterogeneity and crystalline basement depth in the study area. Apart from this, to locate the edges (i.e., geological contacts) or peaks, deriving the source edge function have been estimated using gravity data. Source edge detection with dip and strike orientation have been derived from gravity grid data (Cordell and Grauch 1982, Blakely and Simpson 1986, Grauch and Cordell 1987). 


\section{GEOLOGY AND TECTONICS}

The study area is enfolded with various kinds of geological formations with thrusting and faulting. It is covered by Ganga Basin, Sub Himalaya, Lesser Himalaya, Vaikrita Group, Higher Himalaya, and Tethys Himalaya. The Main Frontal Thrust (MFT) and Main Boundary Thrust (MBT) are located at the south-western part. South Almora Thrust (SAT) and North Almora Thrust are located in the southern part and mostly outside the study area. Main Central Thrust (MCT) divides into multi-faults/thrusts and prominently into two parts, Munsiyari Thrust (MT) and Vaikrita Thrust (VT), which are located at the central part of the study area oriented NW-SE. The MCT has played a role for the Himalayan mountain development. It connects the Greater Himalayan crystalline series over the Lesser Himalayan series. This MCT itself is a wide fault zone and coincides with several string faults.

The Southern Tibetan Detachment System (STDS) is situated in the north-eastern part of the map. The geologic and the tectonic map of the study area is shown in Fig. 3 (after Ghosh and Singh 2014). Patriat and Achache

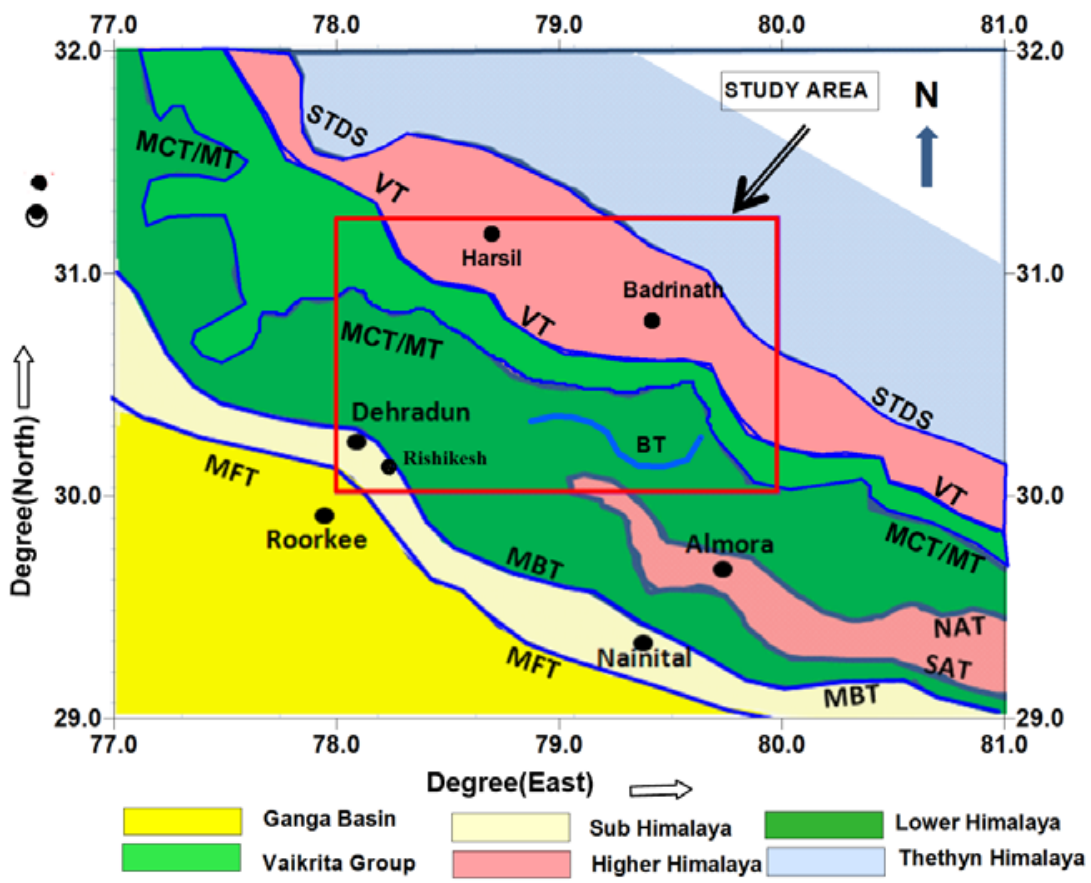

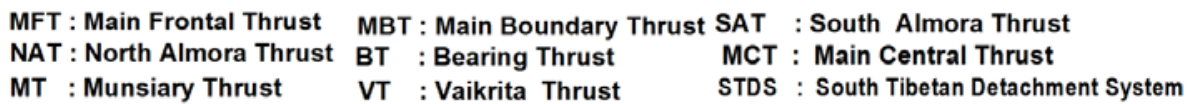

Fig. 3. Geological and tectonic map of the study area (after Ghosh and Singh 2014). 
(1984) observed shortening of continental crust in different incidents like subduction of continental crust, intra continental thrusting, internal deformation and lateral extrusion. Sinha (1987) studied the crustal evolution of collision and compressional belts and the tectonic zonation of Himalaya. The crustal movement of the Indian plate and the Eurasian plate causes the overlapping, shortening, and isostatic adjusted with the Tibetan Plateau. The details overall geological framework of the Himalaya have been provided by Heim and Gansser (1939) and Gansser (1964).

\section{METHODOLOGY: 3D EULER DECONVOLUTION, TILT ANGLE AND TDX ANALYSIS}

Euler deconvolution technique was used to estimate the source depth locations of the gravity or magnetic signature in a region; it was applied to profile or gridded data to solve the Euler's homogeneity equation (Thompson 1982) which states that:

$$
\left(x-x_{0}\right) \frac{d F}{d x}+\left(y-y_{0}\right) \frac{d F}{d y}+\left(z-z_{0}\right) \frac{d F}{d z}=-N F,
$$

where $x_{0}, y_{0}$, and $z_{0}$ are the source depth locations whose gravity field is $F$ measured at $x, y, z$ and $N$ is the Euler's structural index (SI), which is a function of the source geometry of the causative bodies. Source depth has been estimated based on the Euler deconvolution technique applied to the gridded dataset by solving the Euler's homogeneity equation. Equation 1 in this text clearly explains the details of the theory. This depth estimation depends on the type of structural index (SI) which varies from -1 to 2 . In the case of gravity data set, $\mathrm{SI}=-1$ denotes the contact type bodies, $\mathrm{SI}=0$ for thin sheet edge and thin sill dyke, SI $=1$ for cylinder, thin bed and fault, and $\mathrm{SI}=2$ for point or spherical bodies. In this text, we have used $\mathrm{SI}=0$, which is theoretically not accurate but provides approximation of contact type bodies for depth calculation using the first vertical derivative of gravity data.

The Bouguer gravity anomaly across the south-western part to northwestern part shows large deviation from local isostatic equilibrium. The mass deficiency characterizes the Ganga basin and the excess underlies the Lesser Himalaya. It is understood that the Ganga basin supposed to be overcompensated whereas the Himalayas are undercompensated by as much as $158 \mathrm{mGal}$ (Fig. 2). This combination of mass deficiency over the Ganga basin and the excess mass over the Himalaya Mountains is due to isostatic occurrences within the strong Indian lithosphere being flexed down at the Himalayan front and extended beneath the Himalaya. The isostatic regional correction is applied to Bouguer gravity anomaly using Airy's isostasy model where $38 \mathrm{~km}$ crust thickness is considered. However, this $38 \mathrm{~km}$ depth 

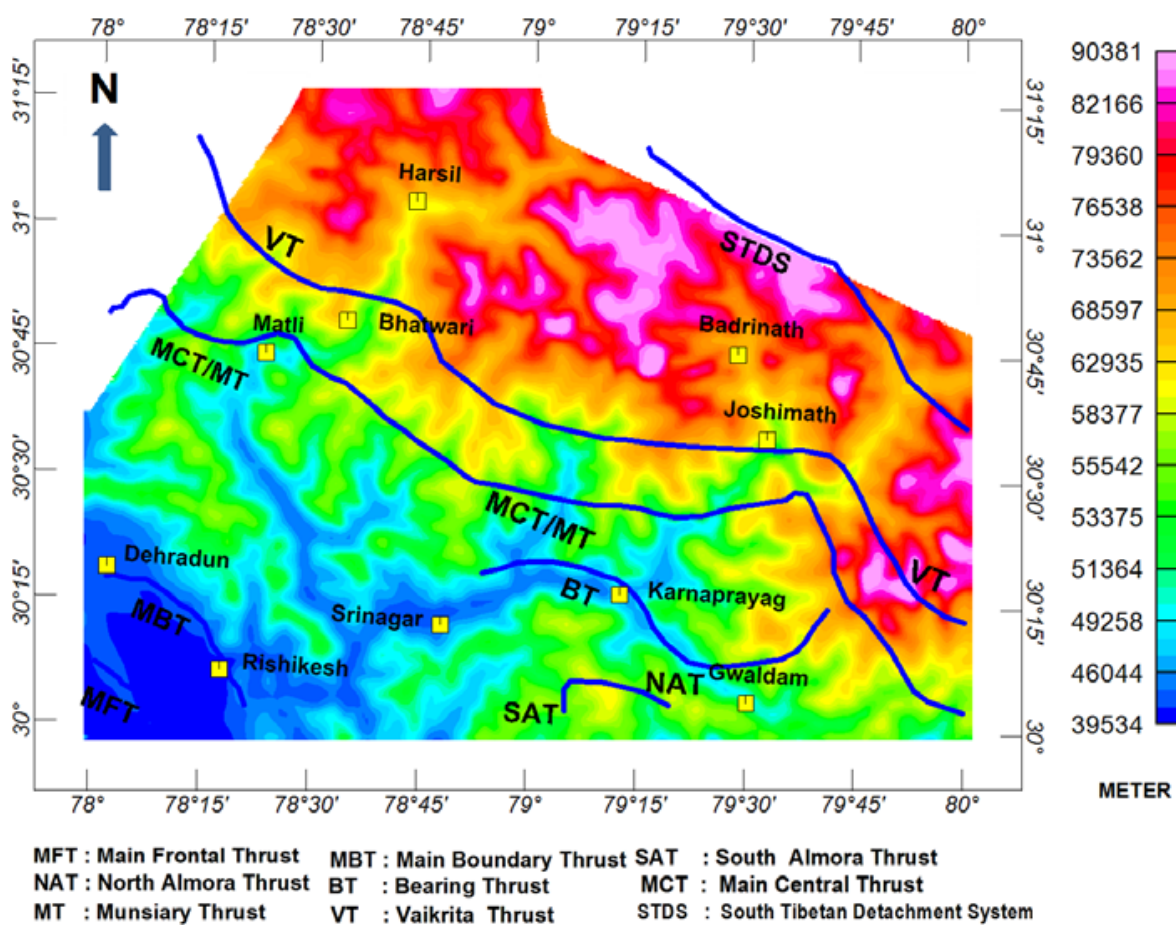

Fig. 4. Isostatic regional depths of the study area (calculated from topo-grid using Airy's isostasy model).

value is not critical and it is varying between 30 and $45 \mathrm{~km}$ (Kaila 1982). Bouguer density is considered to be $2.7 \times 10^{3} \mathrm{~kg} / \mathrm{m}^{3}$ and Moho density contrast is $0.335 \times 10^{3} \mathrm{~kg} / \mathrm{m}^{3}$ (Lyon-Caen and Molnar 1985, Qureshy 2004). Topographic grids are used to calculate the root depth grid below mean sea level by assuming Airy's isostasy for regional anomaly calculation at each grid point (Fig. 4). To calculate the isostatic residual grid, isostatic regional anomaly has been subtracted from the Bouguer gravity anomaly grid after applying upward continuation for $4 \mathrm{~km}$ (Fig. 5). The upward continuation has been studied from 1 to $4 \mathrm{~km}$ to reduce the short wavelength noise of the data and, finally, the $4 \mathrm{~km}$ upward continuation (4 grid cell points) has been applied in this study to smooth the data without changing the physical significance. This corrected isostatic residual anomaly (Fig. 5) is now used to calculate the first vertical gravity gradient (Fig. 6). This first vertical gravity gradient again breaks into three gradients viz. one vertical gravity gradient and others two numbers of horizontal gradient components in $x$ and $y$ directions, respectively. 


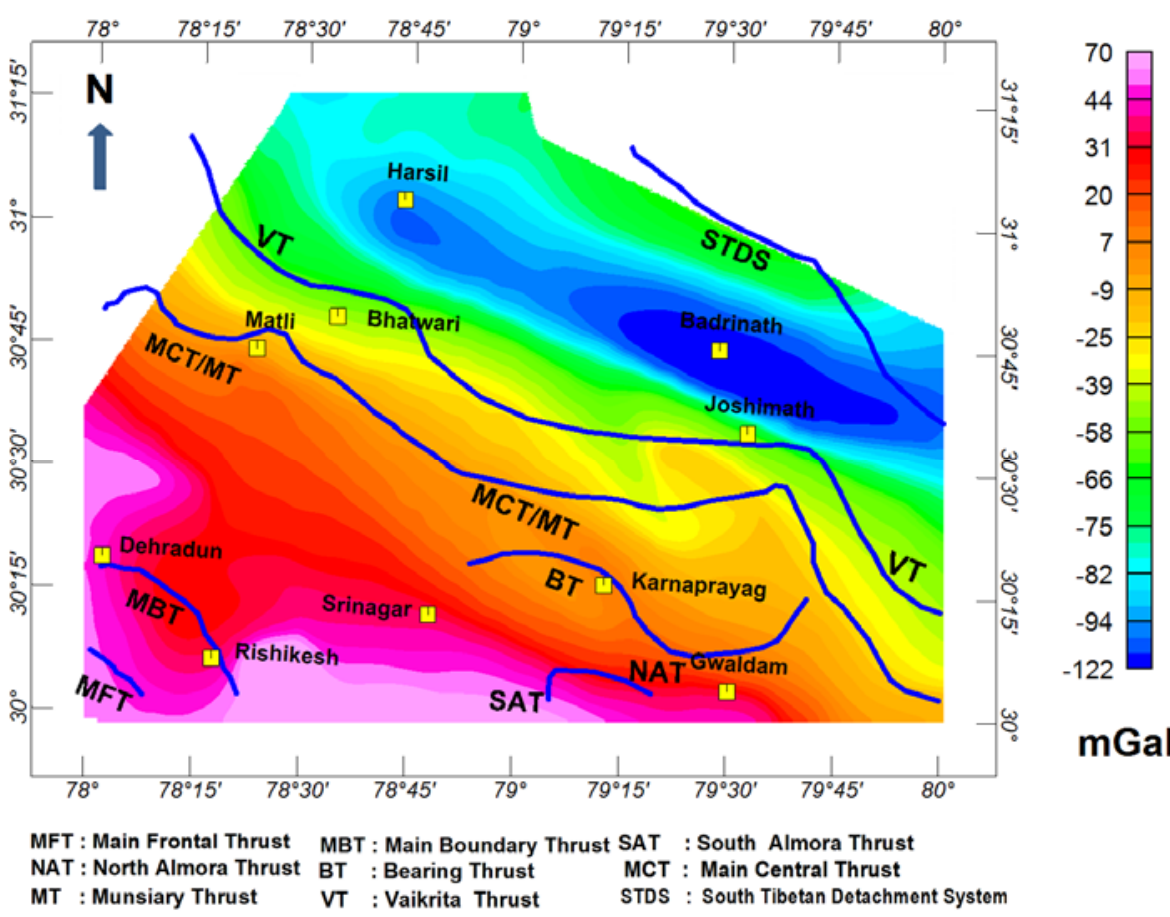

Fig. 5. Isostatic residual map calculated after removing the isostatic regional depth from Bouguer gravity anomaly map and after applying upward continuation of $4000 \mathrm{~m}$. The various thrusts/faults locations are superimposed on the Isostatic residual map.

Structural index (SI) needs to be carefully selected as per the expected geological bodies and structure. Euler depth calculation for fault/contact type bodies used Bouguer gravity anomaly using structural index $\mathrm{SI}=-1$ (Stavrev and Reid 2007, 2010); however, we have used first vertical gravity gradient to calculate Euler depth for fault/contact type bodies using $\mathrm{SI}=0$, which is theoretically not accurate but provides approximated source depth calculation. As Euler deconvolution generates many solutions, so to accept the best results, the knowledge of the geology is very important. It has been observed that the source depth increases with increasing structural index. The Euler source depth solutions are shown by different symbols with color. In this study, we have used structural index $=0$ with a combination of $12 \times 12$ window size (WS) for correlation purpose.

Reid et al. (1990, 2003), and Stavrev (1997) have explained the Euler deconvolution technique, more details in methodology and wider application regarding the Euler's source depth solutions. These Euler depth solutions not 


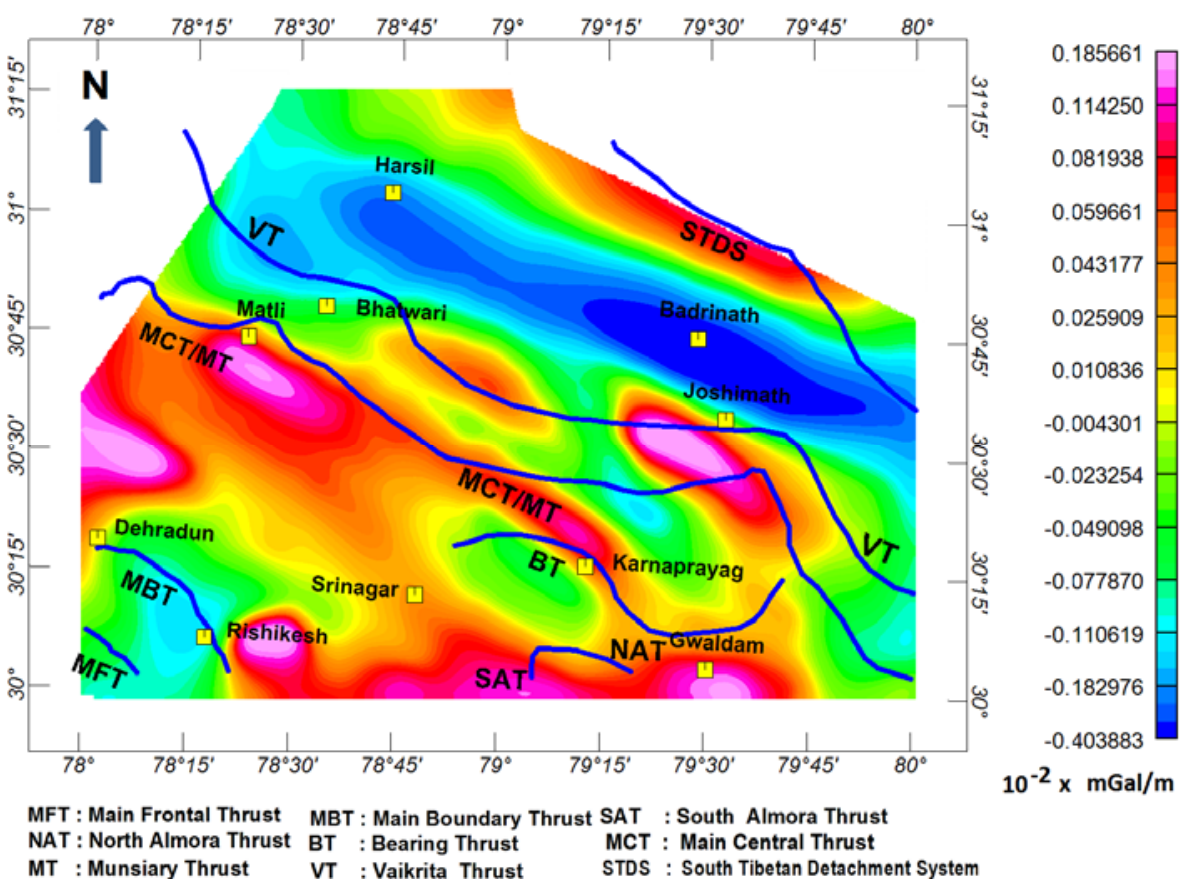

Fig. 6. Map of the first vertical gravity gradient of the study area (vertical gradient calculated from gravity residual isostatic map using Fig. 5).

only estimate the depth $\left(z_{0}\right)$, but also delineate the horizontal boundaries (Wilsher 1987, Corner and Wilsher 1989, Klingele et al. 1991, Marson and Klingele 1993, Huang et al. 1995). In a general case, scattered data points cannot provide superior solutions (Mushayandebvu et al. 2004, Yaghoobian et al. 1993). Various researchers have used 3D Euler deconvolu-tion technique for source depth estimations (Thompson 1982, Pilkington et al. 1995, Smith et al. 1998, Nabighian and Hansen 2001, Cooper 2002, Mikhailov et al. 2003, Milligan et al. 2003, Silva and Barbosa 2003, FitzGerald et al. 2004, Mushayandebvu et al. 2004, Fedi 2007, Melo et al. 2013, Reid and Thurston 2014, Reid et al. 2014).

The tilt angle defined by Miller and Singh (1994) and Verduzco et al. (2004) is as follows

$$
\mathrm{TDR}=\tan ^{-1}\left(\frac{\partial g / \partial z}{\sqrt{(\partial g / \partial x)^{2}+(\partial g / \partial y)^{2}}}\right),
$$


where $\partial g / \partial z$ is the vertical gradient derivative and $\sqrt{(\partial g / \partial x)^{2}+(\partial g / \partial y)^{2}}$ is the horizontal gradient derivative. Tilt angle (TDR) is varying within the range: $+\pi / 2>$ tilt angle $>-\pi / 2$.

The tilt angle is 0 radians at the measuring point $\left(x=x_{0}\right)$ above the edges of the contact. It is evident that this property identifies the horizontal location of the source. In addition, one can determine the depth estimation since the tilt angle equals $\pi / 4$ when $x-x_{0}=z_{0}$ and $-\pi / 4$ when $x-x_{0}=-z_{0}$. Therefore, half the horizontal distance between the $\pm \pi / 4$ radians contours of the tilt angle is the depth to source. In addition, the depth to source can be obtained from the distance between zero and $\pm \pi / 4$ radians at the point $x=x_{0}$ over the vertical contact.

Cooper and Cowan (2006) studied the TDX (horizontal tilt angle) as

$$
\mathrm{TDX}=\tan ^{-1}\left(\frac{\mathrm{THDR}}{\mathrm{VDR}}\right),
$$

where VDR is the vertical gradient and THDR is the total horizontal gradient. TDX is varying between the $+\pi / 2>\mathrm{TDX}>-\pi / 2$, but has a much sharper gradient over the contrast than tilt angle derivatives.

The tilt angle and TDX analyses for thrust and fault locations have been carried out by many researchers (Blakely and Simpson 1986, Miller and Singh 1994, Hsu et al. 1996, Fedi and Florio 2001, Fedi 2002, Williams et al. 2005, Wijns et al. 2005, Phillips et al. 2007, Oruc 2010, Yuanyuan et al. 2010, Ansari and Alamdar 2011, Cascone and Campbell 2012, Fedi et al. 2012).

\section{INTERPRETATION OF GRAVITY DATA}

The present paper describes the analysis of source depth and thrust/fault locations using the gravity data (Qureshy et al. 1974). It has been observed that gradients of Bouguer anomalies increase from Ganga Basin to the Higher Himalaya, varying from 1 to $2 \mathrm{mGal} / \mathrm{km}$. This increases the dipping of Moho rapidly, from $10^{\circ}$ to $15^{\circ}$ beneath the Higher Himalaya and $1^{\circ}$ to $2^{\circ}$ below the Lesser Himalaya (Lyon-Caen and Molnar 1985). The published gravity map of Qureshy et al. (1974) was further digitized with a grid spacing of $1000 \mathrm{~m}$ interval and re-interpreted in terms of geophysical consequences. The isostatic corrected residual anomaly has been calculated after removal of regional and upward continuation of $4 \mathrm{~km}$ from the Bouguer gravity data. The first vertical gradient of the isostatic residual anomaly corrected data is used for further 3D Euler deconvolution (ED), tilt angles, and TDX analysis for depths and horizontal boundary of faults or contact-like bodies. The study area comprises a continuous decreasing gravity anomaly 
trend from south-west to north-east. The lower gravity anomaly is observed in the north-eastern part at Badrinath $(-390 \mathrm{mGal})$, Harsil $(-350 \mathrm{mGal})$, and Joshimath $(-330 \mathrm{mGal})$ area. However, higher gravity anomaly has been observed at the south-western part near Rishikesh (-160 mGal), Dehradun (-160 mGal), and Srinagar (-185 mGal) area. Moderate gravity anomaly $(-260 \mathrm{mGal})$ was observed at Karnaprayag and Matli areas. The Bouguer gravity anomaly decreases from -134 to $-393 \mathrm{mGal}$ while the elevation increases from -199 to $5960 \mathrm{~m}$ from south-western to north-eastern direction (Fig. 1). Bouguer gravity anomaly and the topography of the study area follow the opposite pattern due to isostatic adjustment (Qureshy 1981). Based on this observation, the area can be divided into three parts, viz. lower gravity anomaly in north-eastern part correlates with higher elevation; the higher gravity anomaly in the south-western part correlates with lower elevation, and the moderate gravity anomaly with moderate elevation is between these higher and lower gravity anomalies.

The gravity observations suggest that Bouguer gravity anomaly decreases rapidly from the Ganga Basin to the Greater Himalaya, causing isostatic adjustment and showing a decrease of crustal density. In various places, like Badrinath and Harsil areas, the crystalline rocks are exposed and might be due to the crustal intrusion, tectonic resettlement or movement process. It was suggested that crystalline rocks are uplifted over the sedimentary surfaces near to the thrusted and faulted area. Hence, it is very difficult to find out the accurate thrust and fault locations through the geological studies accurately. The study suggests that these locations are fragmented in multiple locations.

Various authors (Tripathi et al. 2012, Chamoli et al. 2011, Arora et al. 2007, Gokarn et al. 2002) had carried out the depth estimation and provided their views. However, the present study provides better results and detailed information of source depth locations and structural boundaries with dip information. The results carried here are well corroborated with the available thrust fault boundaries, as shown in the tectonic maps of the area (Fig. 10).

Euler solutions are superimposed with the first vertical gradient of the Bouguer gravity map using SI $=0$ and window size (WS) $=12 \times 12$. Different source depth locations are marked with different color circles, which are varying from about 4 to $8 \mathrm{~km}$ (Fig. 7). The Euler deconvolution is also used to estimate the delineation of fault or contact at the different depth levels which corresponds to the fractures of basement. It is noted that upward continuation of $4 \mathrm{~km}$ has been applied to the gravity data, so the total depth of investigation can vary from approximately $8 \mathrm{~km}(\leq 4+4 \mathrm{~km})$ up to $12 \mathrm{~km}$ (maximum depth $8+4 \mathrm{~km}$ ), where the isostatic regional root depth calculated from topo grid is more than $90 \mathrm{~km}$. 


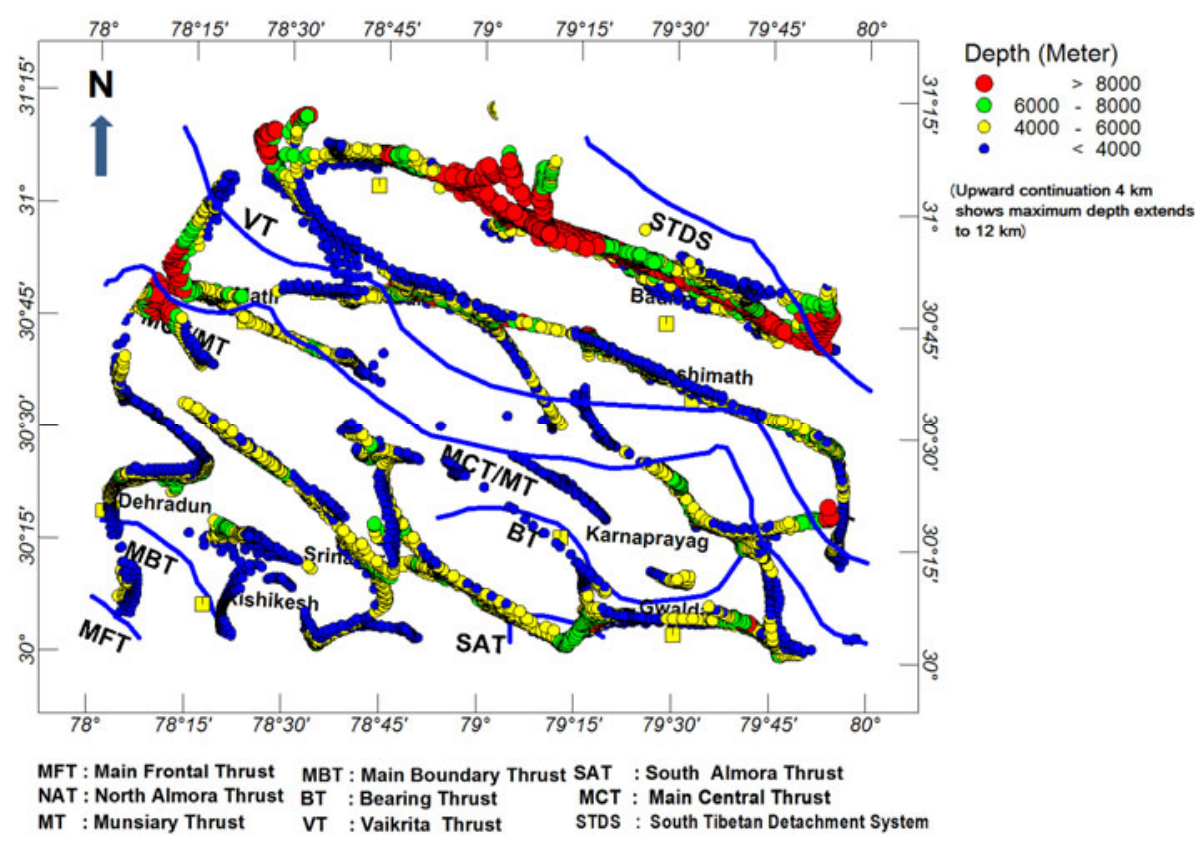

Fig. 7. Map of the Euler source depth solutions superimposed on the geological thrust/fault locations of the Rishikesh-Badrinath area (Euler solutions calculated based on the vertical gravity gradients, $\mathrm{SI}=0$ (structural index), WS $=12 \times 12$ (window size).

The various clusters points of the source bodies are evenly connected from shallow to deeper source depth and vary from about 4 to $8 \mathrm{~km}$ (alternatively adding $4 \mathrm{~km}$ due to upward continuation). It is suggested that the basement depths vary from shallow to the deeper crystalline rocks which are represented in the study. Euler depth solutions are studied from the cluster points located along the thrust boundaries at Main Boundary Thrust (MBT), South Almora Thrust (SAT), North Almora Thrust (NAT), Main Central Thrust (MCT), Munsiary Thrust (MT), Vaikrita Thrust (VT), and South Tibetan Detachment System (STDS). It has been noted that as MCT is a wide fault zone and has divided into several threads faults. However, in broad sense the MCT zone is basically divided into two faults, i.e., upper bounding faults and lower bounding fault. The upper bounding fault is equated with Vaikrita Thrust (VT) and the lower bounding fault is equated as Munsiari Thrust (MT). For this reason, it may be assumed that the 3D Euler deconvolution results in terms of clustering are little scattered. This can also suggests that the thrust/fault boundaries are fragmented in nature, as suggested through Euler deconvolution. Hence, apart from these present thrust 


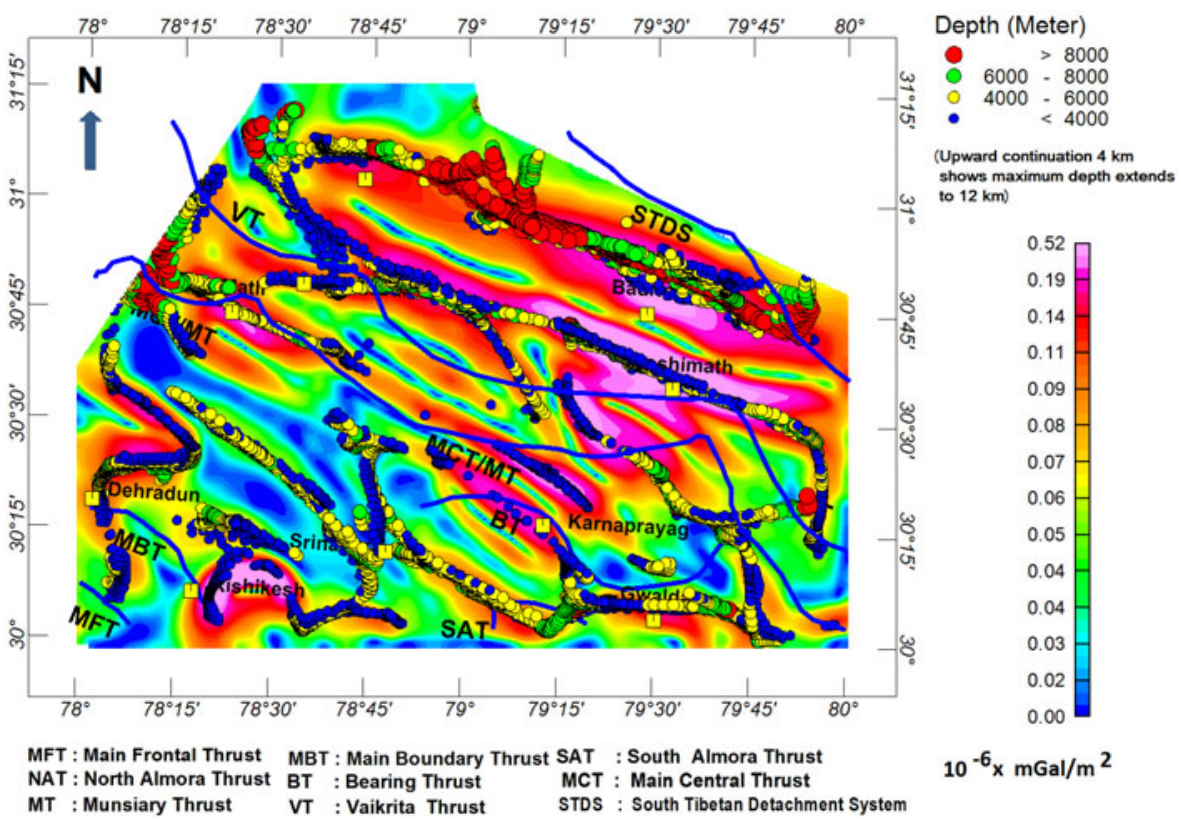

Fig. 8. Map showing the total horizontal component superimposed with the Euler depth solution with $\mathrm{SI}=0$ and $\mathrm{WS}=12 \times 12$.

locations (Fig. 3), more additional thrust/fault boundaries are acknowledged through cluster solutions (Fig. 7). In Badrinath area, shallow depth $<4000 \mathrm{~m}$ suggests the upwarpment of crystalline basement rocks, also observed at the Karnaprayag, Gwaldam, Rishikesh, and Harsil area (Fig. 7).

The horizontal gradient component superimposed with the Euler depth solution SI $=0$ and WS $=12 \times 12$ are shown in Fig. 8. Cluster points are more prominent along the maximum and minimum gradients of gravity field. This horizontal gradient map analysis suggests the trends of major thrust locations and structural boundaries which are poorly exposed. These studies draw attention to weaker structures which can have major tectonic significance in this region. It has been suggested that horizontal gravity gradient analysis with the topography of the area have a strong correlation and need more attention for further study.

Tilt angle and TDX studies suggest the generalized local phase and enhance the weak gravity anomalies. Euler depth solution with structural index 0 and WS $=12 \times 12$ are superimposed on the tilt angle map (Fig. 9) and TDX map (Fig. 10). The tilt angle map is relatively smoother, with positive values over source and zero over the source edges at which the vertical derivatives is zero. TDX also showed the smoother contour along the peak val- 


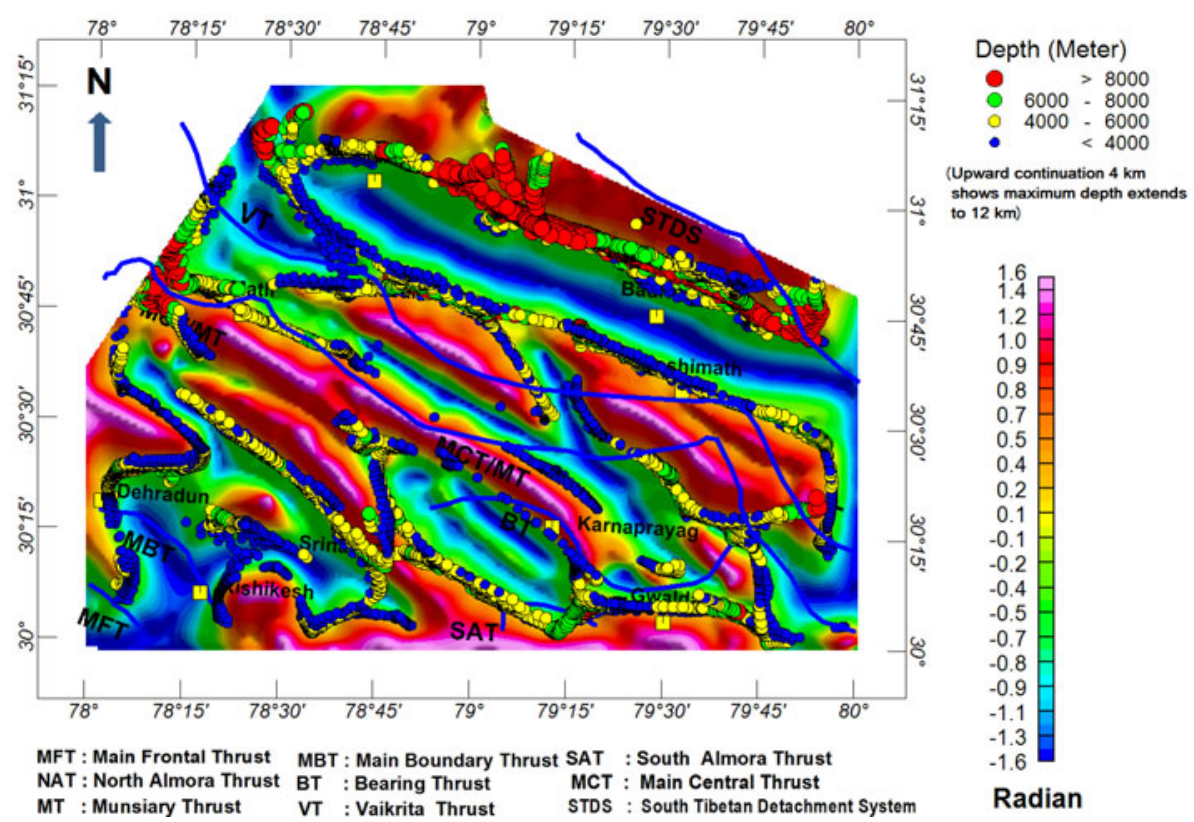

Fig. 9. Map showing the various thrust / fault locations, tilt angle map superimposed with Euler source depth solutions (using $\mathrm{SI}=0$ and $\mathrm{WS}=12 \times 12$ ).

ues. However, in both the cases, tilt angle or TDX studies, the vertical contacts are more clearly defined by the zero contour map. The tilt angle map (Fig. 9) provides the source body boundaries elongated in the north-west to south-east direction, which is well correlated along the different known thrust/fault boundaries. The Source Edge Detection (SED) map was superimposed with dip direction and Euler depth solutions using $\mathrm{SI}=0$ and $\mathrm{WS}=12 \times 12$ (Fig. 11).

The positive and the negative signatures of the gravity anomalies have been considered for processing to estimate in each grid points for calculating dip and strike direction. The map shows the dips of the source bodies with contact representing a symbol " $\perp$ ". The right hand is the dip direction standing on the strike direction (Fig. 11). The long axis represented the strike direction of the edge (contact) and the downward gradient directions are the dip directions as shown in Fig. 11. The map shows the four different strike directions varying from $0^{\circ} \leq$ strike $\leq 90^{\circ}, 90^{\circ} \leq$ strike $\leq 180^{\circ}, 180^{\circ} \leq$ strike $\leq 270^{\circ}$ to $270^{\circ} \leq$ strike $\leq 360^{\circ}$. This strike is measured in the clockwise direction varying from $0^{\circ}$ to $360^{\circ}$, where the $\mathrm{Y}$ axis points to north. Dip can also be measured in degrees, varying from $0^{\circ}-180^{\circ}$ relative to the direction perpendicular to the strike (Blakely and Simpson 1986). 


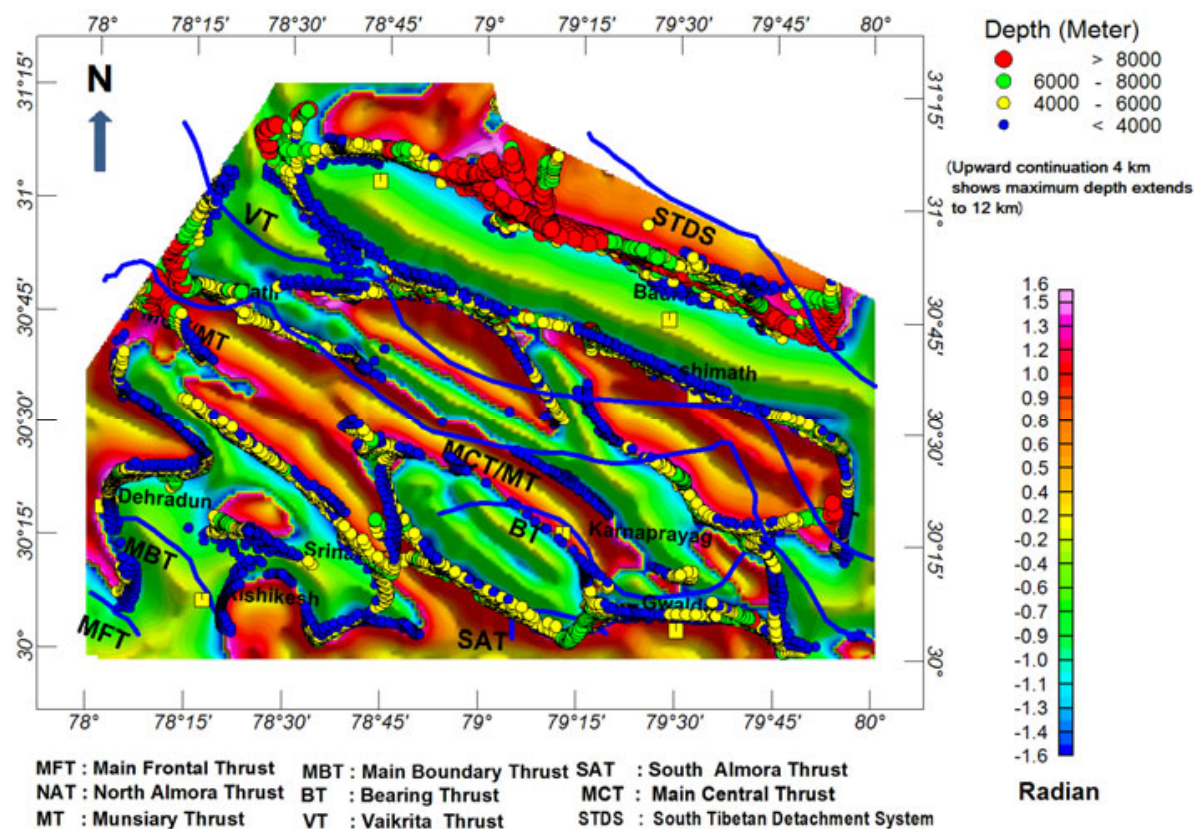

Fig. 10. Map showing the various thrusts/faults locations, TDX (horizontal tilt angle map) superimposed with Euler source depth solutions (using $\mathrm{SI}=0$ and WS $=$ $12 \times 12)$.

The tilt angle map, SED, Euler depth solution $(\mathrm{SI}=0, \mathrm{WS}=12 \times 12)$ and identified thrust/fault boundaries are superimposed, as shown in Fig. 12. Similarly, the TDX analysis, SED, Euler depth solution $(\mathrm{SI}=0, \mathrm{WS}=$ $12 \times 12$ ) and identified thrust/fault boundaries are superimposed, as shown in Fig. 13. These above studies suggest that the various results derived are well correlated.

Reddy and Arora (1993) reported basement depth from 10.0 to $15.0 \mathrm{~km}$ below the Himalayan collision region with a high conductivity layer embedded in the crust at using geomagnetic deep sounding (GDS). Gokarn et al. (2002) also observed the basement depth increases upto $15.0 \mathrm{~km}$ using magnetotelluric (MT) studies. Khattri et al. (1989) also suggested the depth of detachment of 15.0-18.0 km underneath the Lesser Himalaya of Garhwal. Bhattacharya (1999) suggested that during the collision of Indian and Eurasian plate, part of segment of the basement rocks were uplifted from the depth to the surface due to its buoyancy and the rock mass moved along the Main Central Thrust (MCT). It was recommended that most of the collisional stresses were compressive in nature which helped in stirring the mass up and about from the depth. The earthquake's hypocenters are between depths 


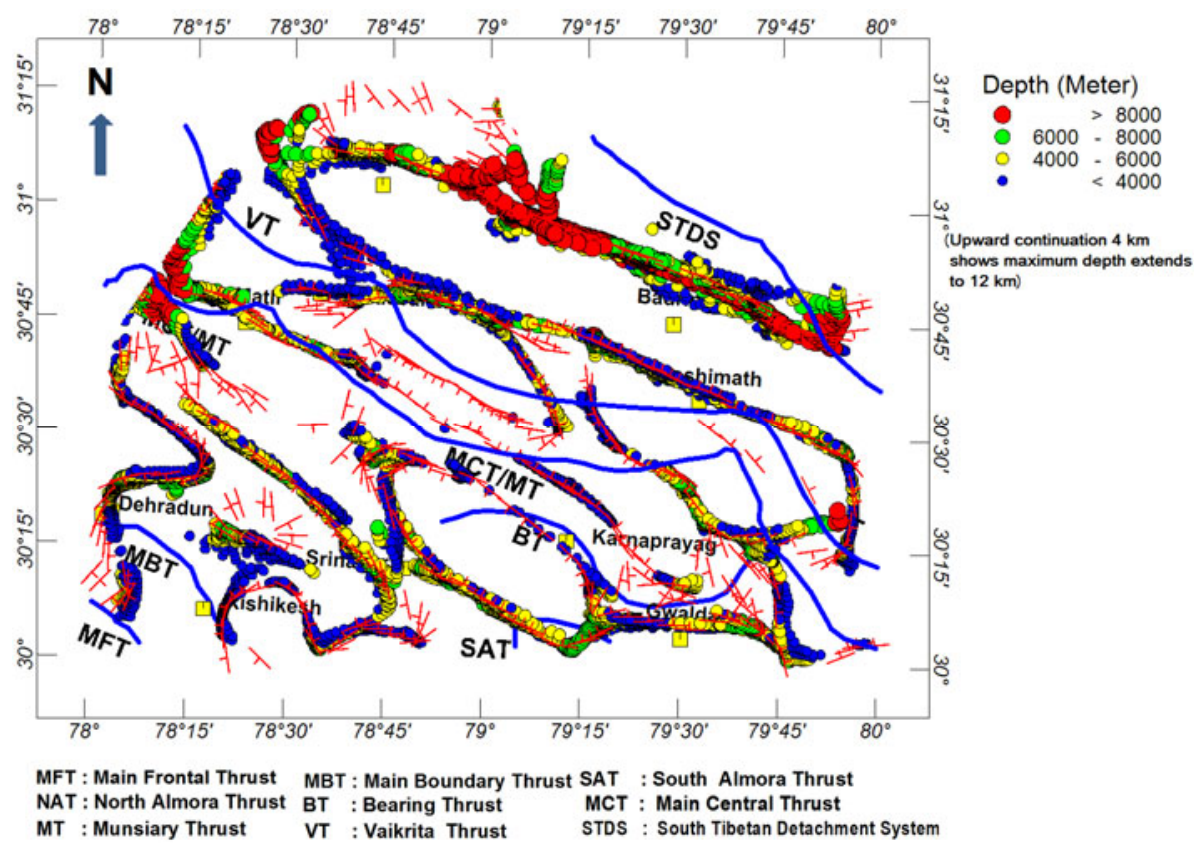

Fig. 11. Map of the Source edge detection (SED) superimposed with dip direction and Euler source depth location $(\mathrm{SI}=0$ and $\mathrm{WS}=12 \times 12)$.

of 10.0 and $20.0 \mathrm{~km}$, due to the under thrusting of Indian Plate and mass upliftment (Molnar and Chen 1982, Ni and Barazangi 1984). Chamoli et al. (2011) have studied the Himalayan detachment thrust to be $11.0 \mathrm{~km}$ in the north-western part of the present study area. Arora et al. (2007) also studied the Deep Resistivity Sounding (DRS) along the western part of the northwestern Himalayas and suggest resistivity $>300 \Omega \cdot \mathrm{m}$ up to depth of $15 \mathrm{~km}$. Tripathi et al. (2012) suggested by coda wave attenuation analysis in the Garhwal region of north-western Himalaya that the earthquakes are mainly concentrated within depths from 10 to $15 \mathrm{~km}$, which suggests that most of the crustal activation takes place within this particular depth. The coeval development of South Tibetan Detachment and the Main Central Thrust studies through simulation analysis and the thrusting dominating nature of Himalaya studies have been done by Shanker et al. (2002).

It can be concluded that the results obtained here are well correlated with the results of various scientists in this study area and neighboring areas (Tripathi et al. 2012, Chamoli et al. 2011, Arora et al. 2007, Gokarn et al. 2002).

The major thrust locations are identical as per the calculation of Source Edge Detection (SED) technique using the vertical gravity gradient data. 


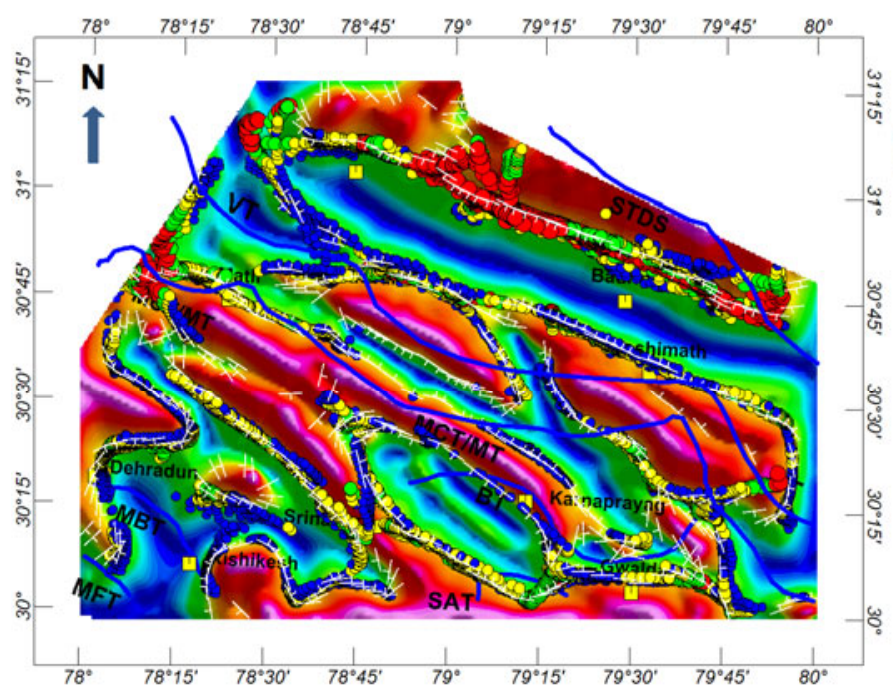

Depth (Meter)

$$
\begin{aligned}
& \text { - } 6000>8000 \\
& \text { - } 4000.8000 \\
& \begin{aligned}
& 4000-6000 \\
- & <4000
\end{aligned}
\end{aligned}
$$
to $12 \mathrm{~km}$ )

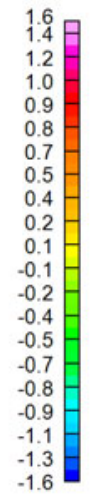

MFT : Main Frontal Thrust MBT : Main Boundary Thrust SAT : South Almora Thrust NAT : North Almora Thrust BT : Bearing Thrust MCT : Main Central Thrust MT : Munsiary Thrust VT : Vaikrita Thrust STDS : South Tibetan Detachment System

Fig. 12. Tilt angle, $\mathrm{SED}$, Euler depth solution $(\mathrm{SI}=0, \mathrm{WS}=12 \times 12)$ and thrust/ fault location map are superimposed which looks a better correlation.

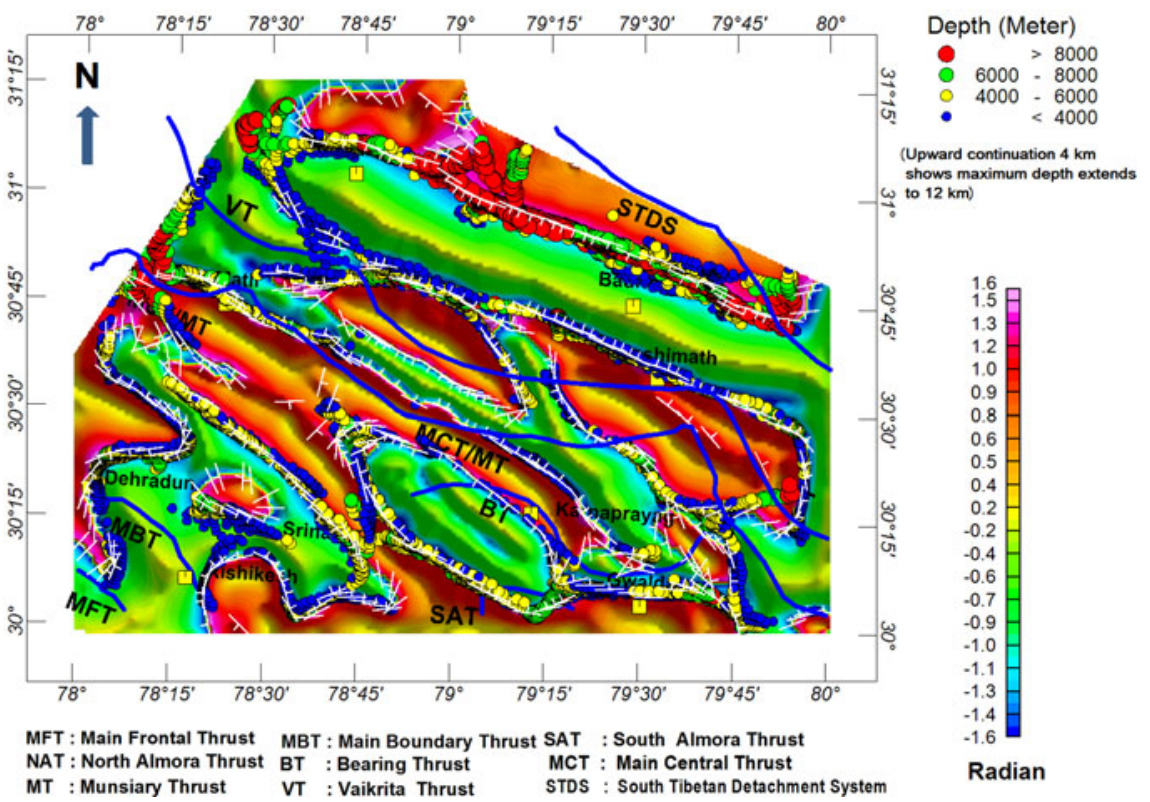

Fig. 13. Map of the Euler source depth solutions $(\mathrm{SI}=0, \mathrm{WS}=12 \times 12)$ superimposed on the geological thrust-fault location of the Rishikesh-Badrinath area, horizontal tilt angle (TDX), and source edge detection (SED). 


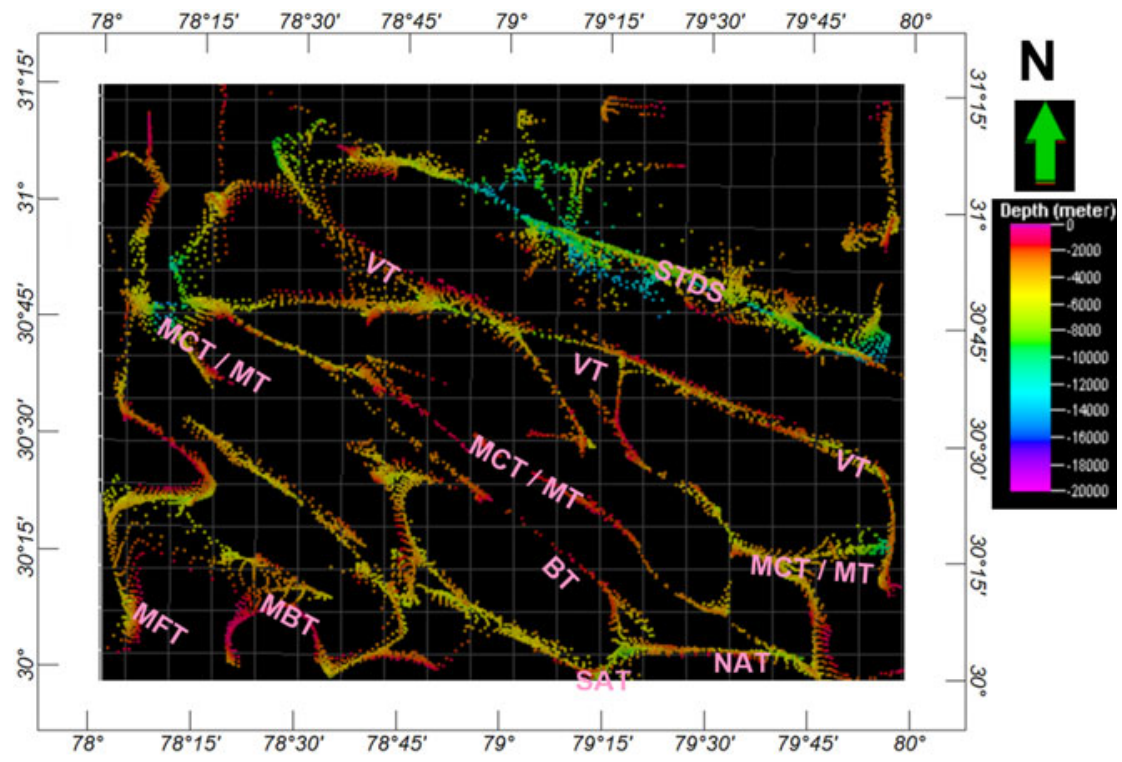

MFT : Main Frontal Thrust MBT : Main Boundary Thrust SAT : South Almora Thrust NAT : North Almora Thrust BT : Bearing Thrust MCT : Main Central Thrust MT : Munsiary Thrust VT : Vaikrita Thrust STDS : South Tibetan Detachment System

Fig. 14. Map shows the tectonic model (front view) using Euler deconvolution by plotting the cluster points and superimposed with the previously known identified thrust locations.

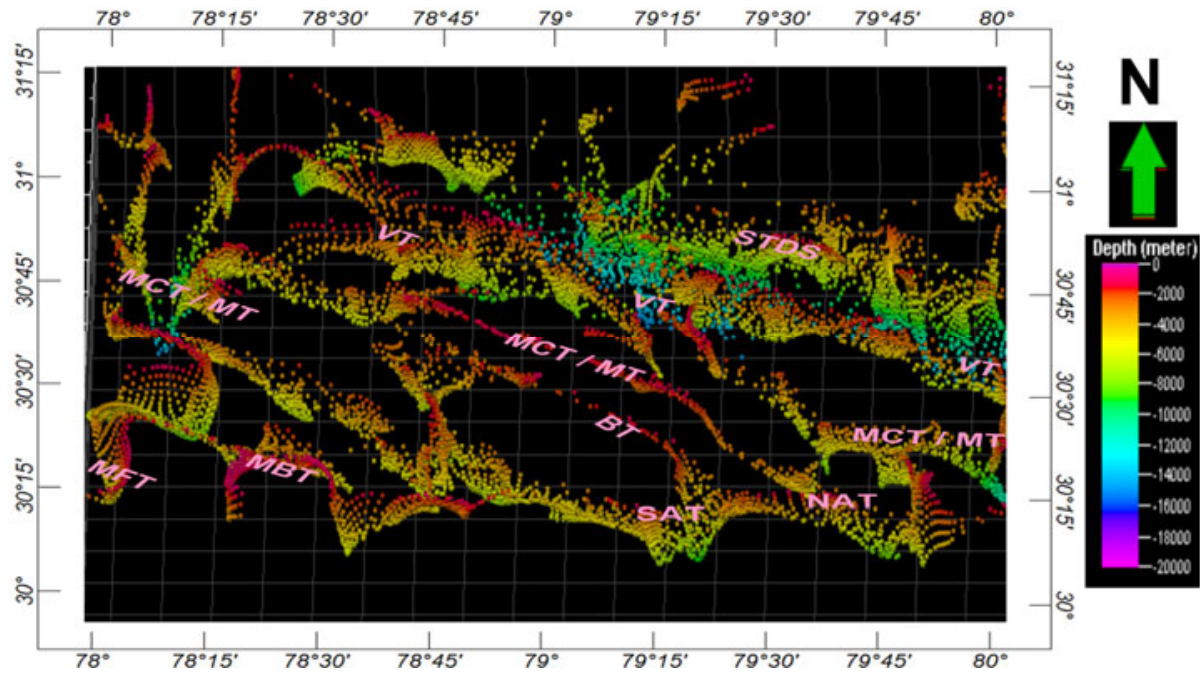

Fig. 15. Map shows the tectonic model (3D view) using Euler deconvolution by plotting the cluster points and superimposed with the previously known identified thrust locations. 

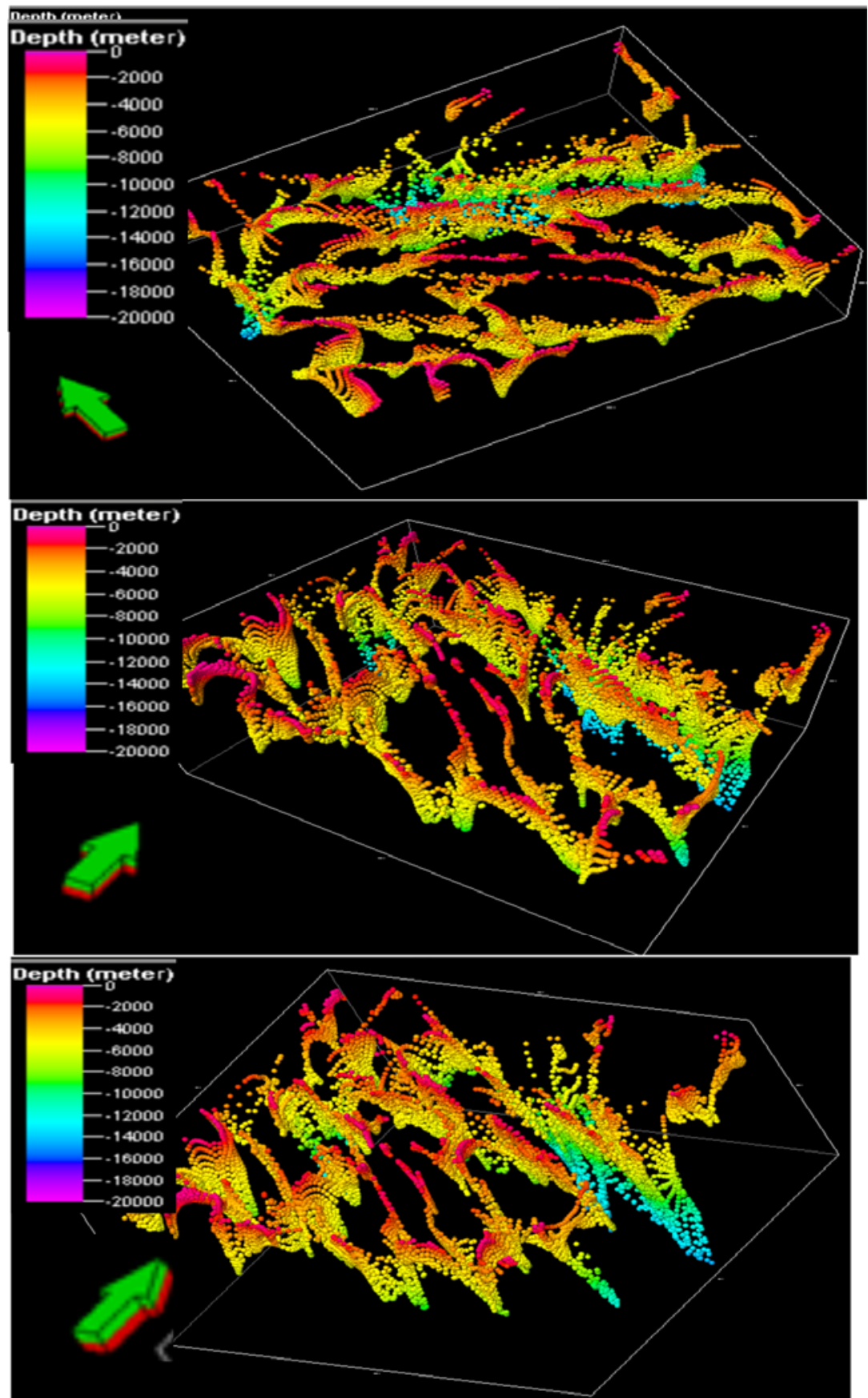

Fig. 16. Map shows the 3D view of the cluster solutions indicating the extension of the cluster points along the thrust locations. 
Most of the derived thrust boundaries are well correlated with the various well known thrust boundaries. However, this study provides more additional thrust boundaries, not noticeable earlier. The details identified automatic thrust locations and the dip directions are shown in Fig. 11. Tilt angle, SED and Euler source depth solutions are shown in Fig. 12, and TDX, SED, and Euler source depth solutions are shown in Fig. 13.

(a)

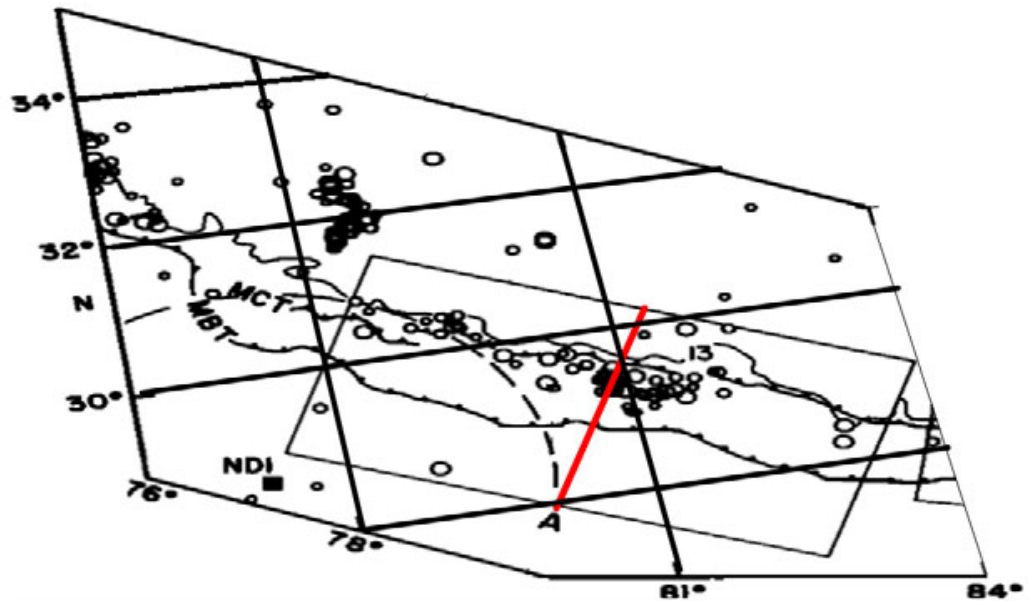

(b)
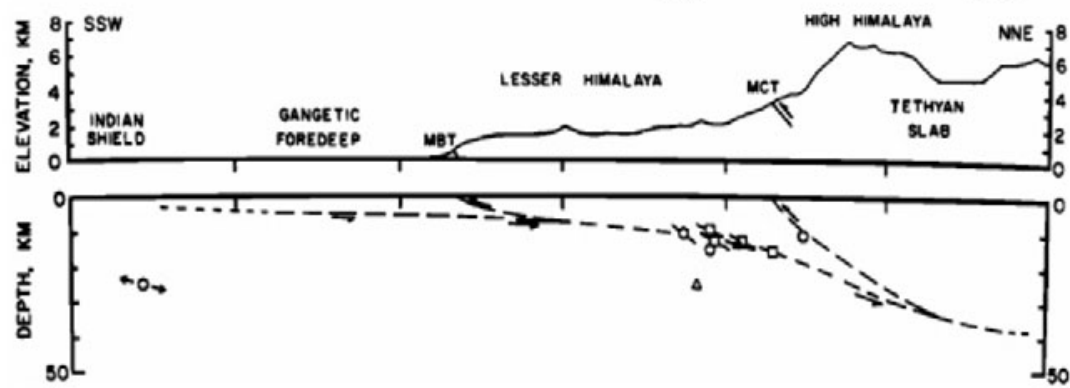

(c)

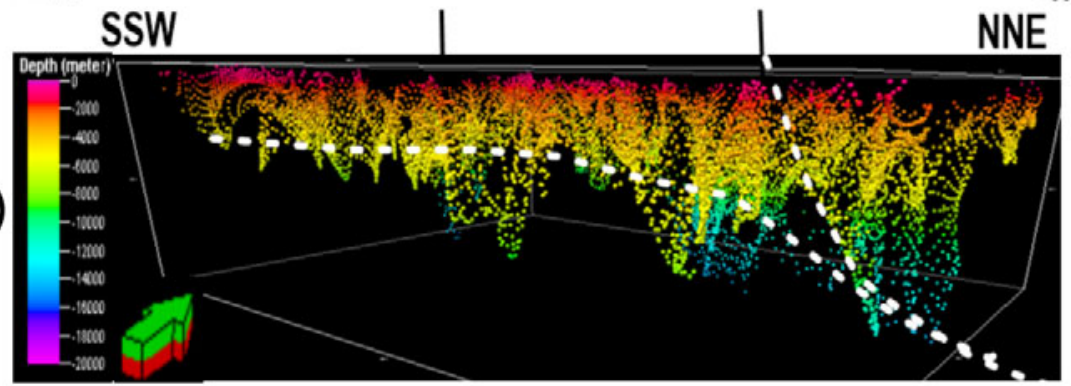

Fig. 17. Map shows the profile location oriented in SSE-NNW direction (profile A) across the area studied by Ni and Barazangi (1984) (a), depth section across the profile A and the relevant thrust locations Ni and Barazangi (1984) (b), and the derived solutions from the 3D Euler deconvolution in the present study(c). 
Additionally, a 3D figure (tectonic model) has been developed showing the position of detachment surface with various thrusts like MFT, MBT, SAT, BT, MCT/MT, VT, and STDS. Figures 14 and 15 show the tectonic model using Euler deconvolution by plotting the cluster points and superimposed with the previously known identified thrust locations. Figure 16 shows the $3 \mathrm{D}$ view of the cluster solutions indicating the extension of the cluster points along the thrust locations. One of the tectonic profiles (Profile A) oriented SSE-NNW generated by $\mathrm{Ni}$ and Barazangi (1984), as shown in Fig. 17a, and the depth solutions model derived by Ni and Barazangi (1984), as shown in Fig. 17b, are correlated with the results derived from the 3D Euler deconvolution (Fig. 17c). The depths estimated along with the thrust locations are well correlated.

It is also to be noted that most of the thrust boundaries in the study area remain unidentified up to now. However, in the present study, additional information of thrust-fault boundaries has been provided. This additional information can be helpful for further detailed geo-scientific research work in the area.

\section{DISCUSSION AND CONCLUSION}

Automatic basement depth study has been carried out using 3D Euler deconvolution of gravity data. These cluster points derived from the Euler's source depth calculation suggest the shallower depth $<8 \mathrm{~km}$ and deeper depth $>12 \mathrm{~km}$ (as data is an upward continuation of $4 \mathrm{~km}$ ). In addition, probable thrust and fault boundaries are identified using tilt angle analysis, TDX angle, and various horizontal gradient analyses of gravity data which have not been marked in the past studies. The Source Edge Detection (SED) technique has been applied and identified the thrust boundaries and dip direction. The various horizontal gradients indicate the structural boundaries in the study area. The information provided in this current study added more supplementary information which was not proposed by earlier study. The results shown here with different aspects are well correlated with the existing available information carried by the various potential workers. However, the present study, providing additional thrust/fault boundary information within Vaikrita Thrust (VT) and Southern Tibetian Detachment System (STDS), with source depth locations and dips directions, provided a need to carry further work with more attention. The gravity data interpretation provides a more reasonable explanation for the depth estimation, structural boundary, and source edge detection. The compilations of details of gravity analysis correlate with the depth and thrust boundaries of buried structures and also clarify the pattern of geological information in the north-western part of India. 
Acknowledgement. I thank to the various authors of the journals/text directly or indirectly for their ideas and inspiration during the course of the work. I also thank the anonymous reviewers/editor for their useful comments.

References

Ansari, A.H., and K. Alamdar (2011), A new edge detection method based on the analytic signal of tilt angle ASTA for magnetic and gravity anomalies, Iran. J. Sci. Technol. 35, A2, 81-88.

Arora, B.R., M.J. Unsworth, and G. Rawat (2007), Deep resistivity structure of the northwest Indian Himalaya and its tectonic implications, Geophys. Res. Lett. 34, 1-4, DOI: 10.1029/2006gl029165.

Beaumont, C., R.A. Jamieson, M.H. Nguyen, and B. Lee (2001), Himalayan tectonics explained by extrusion of low-viscosity crustal channel coupled to focus surface denudation, Nature 414, 6865, 738-742, DOI: 10.1038/414738a.

Bhattacharya, A.R. (1999), Deformational regimes across the Kumaun Himalaya: A study in strain patterns, Gondwana Res. Mem. (Japan) 6, 81-90.

Bhattacharya, A.R., and K. Weber (2004), Fabric development during shear deformation in the Main Central Thrust Zone, NW-Himalaya, India, Tectonophysics 387, 1-4, 23-47, DOI: 10.1016/j.tecto.2004.04.026.

Blakely, R.J., and R.W. Simpson (1986), Approximating edges of source bodies from magnetic or gravity anomalies, Geophysics 51, 7, 1494-1498, DOI: 10.1190/1.1442197.

Bouchez, J.L., and A. Pecher (1981), The Himalayan Main Central Thrust pile and its quartz-rich tectinites in Central Nepal, Tectonophysics 78, 1-4, 23-50, DOI: 10.1016/0040-1951(81)90004-4.

Burg, J.P., M. Brunel, D. Gapais, G.M. Chen, and G.H. Liu (1984), Deformation of leucogranites of the crystalline Main Central Thrust Sheet in southern Tibet China, J. Struct. Geol. 6, 5, 535-542, DOI: 10.1016/0191-8141(84)90063-4.

Cascone, L., and S. Campbell (2012), ACLAS: A new automatic method of defining potential field lineaments using coherency analysis. In: Proc. SEG Annual Meeting, 4-9 November 2012, Las Vegas, USA, SEG-2012-1254.

Chamoli, A., A.K. Pandey, V.P. Dimri, and P. Banerjee (2011), Crustal configuration of the northwest Himalaya based on modeling of gravity data, Pure Appl. Geophys. 168, 5, 827-844, DOI: 10.1007/s00024-010-0149-2.

Cooper, G.R.J. (2002), An improved algorithm for the Euler deconvolution of potential field data, The Leading Edge 21, 12, 1197-1198, DOI: 10.1190/ 1.1536132 . 
Cooper, G.R.J., and D.R. Cowan (2006), Enhancing potential field data using filters based on the local phase, Comput. Geosci. 32, 10, 1585-1591, DOI: 10.1016/j.cageo.2006.02.016.

Cordell, L., and V.J.S. Grauch (1982), Mapping basement magnetization zones from aeromagnetic data in the San Juan Basin, New Mexico. In: Proc. 52nd SEG Annual Meeting, 17-21 October 1982, Dallas, USA, SEG-1982-0246.

Corner, B., and W.A. Wilsher (1989), Structure of the Witwatersrand basin derived from interpretation of the aeromagnetic and gravity data. In: G.D. Garland (ed.), Proc. Exploration '87: Third Decennial Int. Conf. on Geophysical and Geochemical Exploration for Minerals and Groundwater, Ontario Geol. Survey, Special Vol. 3, 532-546.

Fedi, M. (2002), Multiscale derivative analysis: A new tool to enhance gravity source boundaries at various scales, Geophys. Res. Lett. 29, 2, 1029-1032, DOI: $10.1029 / 2001 \mathrm{GL} 013866$.

Fedi, M. (2007), DEXP: A fast method to determine the depth and the structural index of potential fields sources, Geophysics 72, 1, 11-111, DOI: 10.1190/ 1.2399452 .

Fedi, M., and G. Florio (2001), Detection of potential fields source boundaries by enhanced horizontal derivative method, Geophys. Prospect. 49, 1, 40-58, DOI: 10.1046/j.1365-2478.2001.00235.x.

Fedi, M., G. Florio, and L. Cascone (2012), Multiscale analysis of potential fields by a ridge consistency criterion: the reconstruction of the Bishop basement, Geophys. J. Int. 188, 1, 103-114, DOI: 10.1111/j.1365-246X.2011.05259.x.

FitzGerald, D., A.B. Reid, and P. McInerney (2004), New discrimination techniques for Euler deconvolution, Comput. Geosci. 30, 5, 461-469, DOI: 10.1016/ j.cageo.2004.03.006.

Gansser, A. (1964), Geology of the Himalayas, Interscience Publ., London, 289 pp.

Ghosh, G.K., and C.L. Singh (2014), Spectral analysis and Euler deconvolution technique of gravity data to decipher the basement depth in the DehradunBadrinath area, J. Geol. Soc. India 83, 5, 501-512, DOI: 10.1007/s12594014-0077-3.

Gokarn, S.G., C.K. Rao, and G. Gupta (2002), Crustal structure in the Siwalik Himalayas using magnetotelluric studies, Earth Planets Space 54, 1, 19-30, DOI: $10.1186 / \mathrm{BF} 03352418$.

Grasemann, B., H. Fritz, and J.C. Vannay (1999), Quantitative kinematic flow analysis from the Main Central Thrust Zone NW-Himalaya: implications for a decelerating strain path and extrusion of orogenic wedges, J. Struct. Geol. 21, 7, 837-853, DOI: 10.1016/S0191-8141(99)00077-2.

Grauch, V.J.S., and L. Cordell (1987), Limitations on determining density or magnetic boundaries from the horizontal gradient of gravity or pseudogravity data, Geophysics 52, 1, 118-121, DOI: 10.1190/1.1442236. 
Heim, A., and A. Gansser (1939), Central Himalaya: Geological Observations of the Swiss Expedition 1936, Hindustan Publ., Delhi, 284 pp.

Hsu, S.K., J.C. Sibuet, and C.T. Shyu (1996), High resolution detection of geological boundaries from potential field anomalies. An enhanced analytic signal technique, Geophysics 61, 2, 373-386, DOI: 10.1190/1.1443966.

Huang, D., D. Gubbins, R.A. Clark, and K.A. Whaler (1995), Combined study of Euler's homogeneity equation for gravity and magnetic field. In: 57th EAGE Conference and Technical Exhibition; European Association of Exploration Geophysics, Extended abstr., 144, DOI: 10.3997/2214-4609. 201409565.

Kaila, K.L. (1982), Deep seismic sounding studies in India, Geophys. Res. Bull. 20, 3, 309-328.

Khattri, K.N., R. Chander, V.K. Gaur, I. Sarkar, and S. Kumar (1989), New seismological results on the tectonics of the Garhwal Himalaya, Proc. Indian Acad. Sci. Earth Planet Sci. 98, 1, 91-109, DOI: 10.1007/BF02880378.

Klingele, E.E., I. Marson, and H.G. Kahle (1991), Automatic interpretation of gravity gradiometric data in two dimensions: Vertical gradients, Geophys. Prospect. 39, 3, 407-434, DOI: 10.1111/j.1365-2478.1991.tb00319.x.

Le Fort, P. (1975), Himalayas: the collided range. Present knowledge of the continental arc, Am. J. Sci. 275A, 1, 1-44.

Leech, M.L., S. Singh, A.K. Jain, S.L. Klemperer, and R.M. Manickavasagam (2005), The onset of India-Asia continental collision: Early, steep subduction required by the timing of UHP metamorphism in the western Himalaya, Earth Planet. Sci. Lett. 234, 1-2, 83-97, DOI: 10.1016/j.eps1.2005.02. 038 .

Lyon-Caen, H., and P. Molnar (1985), Gravity anomalies, flexure of the Indian plate, and the structure, support and evolution of the Himalaya and Ganga Basin, Tectonics 4, 6, 513-538, DOI: 10.1029/TC004i006p00513.

Marson, I., and E.E. Klingele (1993), Advantages of using the vertical gradient of gravity for 3-D interpretation, Geophysics 58, 11, 1588-1595, DOI: 10.1190/1.1443374.

Melo, F.F., V.C.F. Barbosa, L. Uieda, V.C. Oliveira Jr., and J.B.C. Silva (2013), Estimating the nature and the horizontal and vertical positions of 3D magnetic sources using Euler deconvolution, Geophysics 78, 6, J87-J98, DOI: 10.1190/geo2012-0515.1.

Mikhailov, V., M. Galdeano, A. Gvishiani, S. Agayan, S. Bogoutdinov, E. Graeva, and P. Sailhac (2003), Application of artificial intelligence for Euler solutions clustering, Geophysics 68, 1, 168-180, DOI: 10.1190/1.1543204.

Miller, H.G., and V. Singh (1994), Potential field tilt - a new concept for location of potential field sources, J Appl. Geophys. 32, 2-3, 213-217, DOI: 10.1016/ 0926-9851(94)90022-1. 
Milligan, P.R., P. Petkovic, and B.J. Drummond (2003), Potential-field datasets for the Australian region: their significance in mapping basement architecture, GSA Spec. Pap. 372, 129-139, DOI: 10.1130/0-8137-2372-8.129.

Molnar, P., and W.P. Chen (1982), Seismicity and mountain building. In: K. Hsu (ed.), Mountain Building Processes, Academic Press, London, 41-57.

Molnar, P., W.P. Chen, T.J. Fitch, P. Tapponier, W.E.K. Warsi, and F.T. Wu (1977), Structure and tectonics of the Himalaya: a brief summary of relevant geophysical observations, Colloq. Inter. CNRS 268, 269-294.

Mushayandebvu, M.F., V. Lesur, A.B. Reid, and J.D. Fairhead (2004), Grid Euler deconvolution with constraints for 2D structures, Geophysics 69, 2, 489496, DOI: $10.1190 / 1.1707069$.

Nabighian, M.N., and R.O. Hansen (2001), Unification of Euler and Werner deconvolution in three dimensions via the generalized Hilbert transform, Geophysics 66, 6, 1805-1810, DOI: 10.1190/1.1487122.

Ni, J., and M. Barazangi (1984), Seismotectonics of the Himalaya Collision Zone: Geometry of the underthrusting Indian Plate beneath the Himalaya, J. Geophys. Res. 89, B2, 1147-1164, DOI: 10.1029/JB089iB02p01147.

Oruc, B. (2010), Edge detection and depth estimation using a tilt angle map from gravity gradient data of the Kozakl1-Central Anatolia Region, Turkey, Pure Appl. Geophys. 168, 10, 1769-1780, DOI: 10.1007/s00024-010-0211-0.

Patriat, P., and J. Achache (1984), India-Eurasia collision chronology has implications for crustal shortening and driving mechanism of plates, Nature 311, 5987, 615-621, DOI: 10.1038/311615a0.

Phillips, J.D., R.O. Hansen, and R.J. Blakely (2007), The use of curvature in potential-field interpretation, Explor. Geophys. 38, 2, 111-119, DOI: 10.1071/ EG07014.

Pilkington, M., A. Abdoh, and D.R. Cowan (1995), Pre-Mesozoic structure of the Inner Moray Firth Basin: constraints from gravity and magnetic data, First Break 13, 7, 291-300, DOI: 10.3997/1365-2397.1995015.

Qureshy, M.N. (1981), Gravity anomalies, isostasy and crust mantle relations in the Deccan Trap and contiguous regions, India. In: K.V. Subha Rao and R.N. Sukheswala (eds.), Deccan Volcanism and Related Basalt Provinces in Other Parts in the World, Geological Society of India, Bangalore, 184197.

Qureshy, M.N. (2004), Geophysical Framework of India, Bangladesh and Pakistan, Narosa Publication, 200 pp.

Qureshy, M.N., S.V. Venkatachalam, and C. Subrahmanyam (1974), Vertical tectonics in Middle Himalaya: an appraisal from recent gravity data, Bull. Geol. Soc. Amer. 85, 6, 921-026, DOI: 10.1130/0016-7606(1974)85<921: VTITMH $>2.0 . \mathrm{CO} ; 2$. 
Reddy, C.D., and B.R. Arora (1993), Quantitative interpretation of geomagnetic induction response across the thrust zones of Himalaya along the Ganga Yamuna valley, J. Geomag. Geoelectr. 45, 9, 775-785.

Reid, A.B., and J.B. Thurston (2014), The structural index in gravity and magnetic interpretation: Errors, uses, and abuses, Geophysics 79, 4, J61-J66, DOI: 10.1190/GEO2013-0235.1.

Reid, A.B., J.M. Allsop, H. Granser, A.J. Millett, and I.W. Somerton (1990), Magnetic interpretation in three dimensions using Euler deconvolution, Geophysics 55, 1, 80-91, DOI: 10.1190/1.1442774.

Reid, A.B., D. FitzGerald, and P. McInerny (2003), Euler deconvolution of gravity data. In: Proc. 73rd SEG Annual International Meeting, 26-31 October 2003, Dallas, USA, SEG-2003-0580.

Reid, A.B., J.O. Ebbing, and S.J. Susan (2014), Avoidable Euler errors - the use and abuse of Euler deconvolution applied to potential fields, Geophys. Prospect. 62, 5, 1162-1168, DOI: 10.1111/1365-2478.12119.

Shanker, D., N. Kapur, and B. Singh (2002), Thrust-wedge mechanics and coeval development of normal and reverse faults in the Himalayas, J. Geol. Soc. London 159, 3, 273-280, DOI: 10.1144/0016-764901-059.

Silva, J.B.C., and V.C.F. Barbosa (2003), 3D Euler deconvolution: Theoretical basis for automatically selecting good solutions, Geophysics 68, 6, 1962-1968, DOI: $10.1190 / 1.1635050$.

Sinha, A.K. (1987), Tectonic zonation of the Central Himalayas and the Crustal evolution of collision and compressional belts, Tectonophysics 134, 1-3, 59-74, DOI: 10.1016/0040-1951(87)90249-6.

Smith, R.S., J.B. Thurston, T.F. Dai, and I.N. MacLeod (1998), iSPI ${ }^{\mathrm{TM}}-\mathrm{The}^{\mathrm{im}-}$ proved source parameter imaging method, Geophys. Prospect. 46, 2, 141151, DOI: 10.1046/j.1365-2478.1998.00084.x.

Stavrev, P.Y. (1997), Euler deconvolution using differential similarity transformations of gravity and magnetic anomalies, Geophys. Prospect. 45, 2, 207246, DOI: 10.1046/j.1365-2478.1997.00331.x.

Stavrev, P., and A. Reid (2007), Degrees of homogeneity of potential fields and structural indices of Euler deconvolution, Geophysics 72, 1, L1-L2, DOI: 10.1190/1.2400010.

Stavrev, P., and A. Reid (2010), Euler deconvolution of gravity anomalies from thick contact/fault structures with extended negative structural index, Geophysics 75, 6, 151-158, DOI: 10.1190/1.3506559.

Thompson, D.T. (1982), EULDPH: A new technique for making computer assisted depth estimates from magnetic data, Geophysics 47, 1, 31-37, DOI: 10.1190/1.1441278.

Tripathi, J.N., P. Singh, and M.L. Sharma (2012), Variation of seismic coda wave attenuation in the Garhwal region, northwestern Himalaya, Pure Appl. Geophys. 169, 1, 71-88, DOI: 10.1007/s00024-011-0316-0. 
Vannay, J.C., and B. Grasemann (2001), Himalayan inverted metamorphism and syn-convergence extension as a consequence of a general shear extrusion, Geol. Mag. 138, 3, 253-276, DOI: 10.1017/S0016756801005313.

Verduzco, B., J.D. Fairhead, C.M. Green, and C. MacKenzie (2004), New insights into magnetic derivatives for structural mapping, The Leading Edge 23, 2, 116-119, DOI: 10.1190/1.1651454.

Wijns, C., C. Perez, and P. Kowalczyk (2005), Theta Map: Edge detection in magnetic data, Geophysics 70, 4, L39-L43, DOI: 10.1190/1.1988184.

Williams, S.E., J.D. Fairhead, and G. Flanagan (2005), Comparison of grid Euler deconvolution with and without 2D constraints using a realistic 3D magnetic basement model, Geophysics 70, 3, L13-L21, DOI: 10.1190/ 1.1925745 .

Wilsher, W.A. (1987), A structural interpretation of the Witwatersrand basin through the application of automated depth algorithms to both gravity and aeromagnetic data, M.Sc. Thesis, University of Witwatersrand, Johannesburg, South Africa.

Yaghoobian, A., G.A. Boustead, and T.M. Dobush (1993), Object delineation using Euler's momogeneity equation: Location and depth determination of buried ferro-metallic bodies. In: Proc. Symp. on Application of Geophysics to Engineering and Environmental Problems 1993, San Diego, USA, 613-632, DOI: $10.4133 / 1.2922042$.

Yuanyuan, L., Y. Yushan, and L. Tianyou (2010), Derivative-based techniques for geological contact mapping from gravity data, J. Earth Sci. 21, 3, 358-364, DOI: $10.1007 / \mathrm{s} 12583-010-0099-8$. 